\title{
Antioxidant and anti-inflammatory effects of DHK-medicated serum on high glucose-induced injury in endothelial cells
}

\author{
ZIYANG ZHANG $^{1}$, WENPEI CHEN ${ }^{1}$, YANDONG WANG ${ }^{2}$, TIANQIN XIONG ${ }^{1}$, \\ CHENGHAO ZHOU ${ }^{1}$, XIAOLAN YAO ${ }^{1}$ and BAOQIN LIN ${ }^{1}$ \\ ${ }^{1}$ School of Chinese Materia Medica, Guangzhou University of Chinese Medicine, Guangzhou, Guangdong 510006; \\ ${ }^{2}$ Zhongshan Ophthalmic Center, Sun Yat-Sen University, Guangzhou, Guangdong 510060, P.R. China
}

Received August 4, 2016; Accepted July 18, 2017

DOI: $10.3892 / \mathrm{mmr} .2017 .7571$

\begin{abstract}
It has been shown that oxidative damage and inflammation caused by hyperglycemia in endothelial cells are key factors triggering diabetic vascular complications. The aim of the present study was to investigate the antioxidant and anti-inflammatory effects of Danhong Huayu Koufuye (DHK)-medicated serum on high glucose (HG)-induced injury in endothelial cells, and examine its underlying mechanisms. EA. hy926 cells were treated with normal glucose, $\mathrm{HG}$, or HG with DHK-medicated serum. Cell viability was assessed using the MTT method. Apoptosis was detected using flow cytometry. Intracellular reactive oxygen species (ROS) levels were measured using the 2',7'-dichlorodihydrofluorescein method. Cell culture supernatant was collected for detecting the activities of glutathione peroxidase (GPx) and superoxide dismutase (SOD), and the levels of malondialdehyde (MDA). The protein expression levels of intercellular adhesion molecule-1 (ICAM-1), nuclear factor $-\kappa \mathrm{B}(\mathrm{NF}-\kappa \mathrm{B})$, hypoxia-inducible factor- $1 \alpha$ (HIF-1 $\alpha$ ) and vascular endothelial growth factor (VEGF) were determined using western blot analysis. The results revealed that DHK-medicated serum accelerated the proliferation and inhibited the apoptosis of cells treated with $\mathrm{HG}(\mathrm{P}<0.01)$ in a dose-dependent manner. Compared with the HG group, the high levels of ROS and MDA were significantly reduced by DHK-medicated serum $(\mathrm{P}<0.01)$. A $10 \%$ concentration of DHK-medicated serum increased the activities of SOD and GPX by 59.4 and $95.5 \%$, respectively. The high protein expression levels of ICAM-1, NF- $\kappa$ B, VEGF and HIF-1 $\alpha$ were significantly ameliorated by DHK-medicated serum ( $\mathrm{P}<0.01$, vs. HG group). These findings indicated that DHK-medicated serum protected EA. hy926 cells from HG-induced injury and apoptosis through antioxidation and anti-inflammatory effects.
\end{abstract}

Correspondence to: Professor Baoqin Lin, School of Chinese Materia Medica, Guangzhou University of Chinese Medicine, 232 Wai Huan East Road, Guangzhou, Guangdong 510006, P.R. China

E-mail: linbaoqin@gzucm.edu.cn

Key words: high glucose, Danhong Huayu Koufuye, oxidative stress, EA. hy926 cells, apoptosis, inflammation

\section{Introduction}

Diabetes mellitus (DM) is characterized by chronic high blood glucose, which causes injuries to vessels and lead to the development of vascular complications in tissues, including the heart, kidney and eye (1-4). The vascular complications of diabetes have become a serious health concern in humans.

The damage of endothelial cells is observed in the early stages of diabetic vascular complications (1,3-6). The endothelial dysfunction, which is triggered by hyperglycemia, includes increased endothelial oxidative stress, inflammation and cell apoptosis, decreased nitric oxide (NO) bioavailability, and high expression levels of hypoxia-inducible factor-1 $\alpha$ (HIF-1 $\alpha)$ and vascular endothelial growth factor (VEGF) $(1,5,6)$. Increasing evidence indicates that endothelial dysfunction is important in the pathogenesis of diabetic vascular complications $(2,3)$.

The levels of superoxide are elevated and the activities of antioxidant defense substances are reduced in the vessels of diabetic patients and rats, and in endothelial cells exposed to high glucose (HG) (7-10). Elevated oxidative stress may cause injuries in vascular endothelial cells during the process of diabetic vascular complications (11-13). Excessive reactive oxygen species (ROS) and lipid peroxide initiate and promote endotheliocyte damage $(1,7)$. The antioxidant status of diabetic patients is crucial in preventing oxidative stress and the process of vascular complications. Antioxidative enzymes, including superoxide dismutase (SOD), glutathione peroxidase (GPx) and catalase (CAT), inhibit the generation of ROS (14-17), which prevents against endothelial cell injury. Therefore, the correlations among hyperglycemia, redox imbalance and oxidative stress constitute the main pathological mechanism underlying diabetic vascular complications (2).

There are several similarities between diabetic vascular complications and chronic inflammatory diseases $(7,10)$. The inflammation triggered by hyperglycemia can cause damage to endothelial cells, which then increases vascular permeability and accelerates the release of proinflammatory mediators $(18,19)$. Nuclear factor $-\kappa \mathrm{B}(\mathrm{NF}-\kappa \mathrm{B})$, activated by hyperglycemia, elevates the levels of proinflammatory mediators, including intercellular adhesion molecule-1 (ICAM-1), interleukins (ILs), VEGF and tumor necrosis factor- $\alpha$ (TNF- $\alpha)(18-20)$. Therefore, 
inflammation and diabetic vascular complications are linked, and excessive inflammatory factors may predict the onset and progression of diabetic vascular complications.

Danhong Huayu Koufuye (DHK) has long been used clinically in China (21-24). It contains $29 \%$ Salvia miltiorrhiza radix, 11.5\% Angelicae sinensis radix, 15\% Chuanxiong rhizoma, $11.5 \%$ Persicae semen, $11.5 \%$ Carthami flos, $11.5 \%$ Bupleuri radix and $10 \%$ Aurantii fructus. DHK had the ability to promote blood circulation to overcome blood stasis and, in Traditional Chinese medicine, is believed to promote qi circulation and remove meridian obstruction. Our previous studies showed that DHK prevented the process of diabetic retinopathy in diabetic Sprague-Dawley (SD) (22) and Zucker diabetic fatty (ZDF) rats (23). It was also found that DHK inhibited the formation of deep venous thrombosis via anti-inflammatory activity in rats (24).

The present study investigated the protective effect of DHK-medicated serum on HG-induced injury and apoptosis in EA. hy926 cells, and examined whether the antioxidative and anti-inflammatory activities of DHK were involved in the mechanisms.

\section{Materials and methods}

Materials. DHK was provided by Hutchison Whampoa Guangzhou BaiyunshanChinese MedicineCo.,Ltd.(Guangzhou, China). Pentobarbital sodium salt and xylazine hydrochloride injection were purchased from Merck Serono Co., Ltd. (Beijing, China) and Dunhua Shengda Pharmaceutical Co., Ltd. (Dunhua, China), respectively. Cell culture reagents, including Dulbecco's modified Eagle's medium (DMEM), penicillin and streptomycin were purchased from Gibco; Thermo Fisher Scientific, Inc. (Waltham, MA, USA), and fetal bovine serum (FBS) was obtained from Biological Industries (Kibbutz Beit Haemek, Israel). The Annexin V/Fluorescein Isothiocyanate Apoptosis Detection kit was purchased from eBioscience, Inc. (San Diego, CA, USA). 2',7'-Dichlorodihydrofluorescein diacetate $\left(\mathrm{H}_{2} \mathrm{DCFDA}\right)$ was purchased from Sigma-Aldrich; Merck KGaA (Darmstadt, Germany). The SOD assay kit, thiobarbituric acid reactive substance (TBARS) assay kit and GPx assay kit were purchased from Cayman Chemical Company (Ann Arbor, MI, USA). Rabbit polyclonal antibodies against ICAM-1 (cat. no. ab7815), NF-кB (cat. no. ab28835), HIF-1 $\alpha$ (cat. no. ab82832), glyceraldehyde-3-phosphate dehydrogenase (GAPDH; cat. no. ab37168), and goat anti-rabbit IgG conjugated with horseradish peroxidase (cat. no. ab6721) were purchased from Abcam (Cambridge, UK). The rabbit polyclonal antibody against VEGF (cat. no. sc507) was purchased from Santa Cruz Biotechnology, Inc. (Santa Cruz, CA, USA). Enhanced chemiluminescence (ECL) reagent was purchased from Pierce; Thermo Fisher Scientific, Inc.

Animals. Male SD rats (200-250 g; n=10) were obtained from the Experimental Animal Center, Guangzhou University of Chinese Medicine (Guangzhou, China). All rats (approval no. SCXK 2013-0020) had free access to a standard diet and drinking water, and were housed in a room at $24.0 \pm 0.5^{\circ} \mathrm{C}$ and with a 12:12 h light/dark schedule. The experiments were performed in accordance with the Animal Ethics Committee of Guangzhou University of Chinese Medicine.
Cell culture. EA. hy926 cells, a hybrid human umbilical vein endothelial cell line, were purchased from the Type Culture Collection of the Chinese Academy of Sciences (Shanghai, China). The cells were cultured in DMEM with $5 \mathrm{mM}$ glucose, essential and non-essential amino acids $(8.9 \mathrm{mg} / \mathrm{l}$ L-alanine, $13.3 \mathrm{mg} / 1$ aspartic acid, $15 \mathrm{mg} / 1 \mathrm{~L}$-asparagine, $14.7 \mathrm{mg} / 1$ monosodium glutamate and $11.5 \mathrm{mg} / \mathrm{l}$ proline), sodium selenite $(0.02 \mathrm{mg} / \mathrm{l})$, ascorbic acid (10 mg/l), 10\% FBS (v/v) and antibiotics (100 Ul penicillin and $100 \mathrm{mg} / \mathrm{l}$ streptomycin) at $37^{\circ} \mathrm{C}$ in an atmosphere containing $5 \% \mathrm{CO}_{2}$ and $95 \%$ air. EA. hy926 cells at passages 3-5 were used in all experiments.

Preparation of DHK-medicated serum. The rats were randomly divided into two groups: Vehicle group and DHK group, in which the rats were intragastrically administered with distilled water or DHK $(3.20 \mathrm{ml} / \mathrm{kg})$, respectively, for 5 days consecutively (once per day). Blood was collected from the carotid artery $1 \mathrm{~h}$ following the fifth administration, and was centrifuged at $1,000 \mathrm{x} \mathrm{g}$ at room temperature for $10 \mathrm{~min}$ to obtain serum. The serum was sterilized at $56^{\circ} \mathrm{C}$ for $30 \mathrm{~min}$, and then mixed with complete medium to prepare the DHK-medicated serum, according to the volume ratio (v/v) to give $1,5,10$ and $20 \%$ solutions.

Cell viability assay. The viability of EA. hy926 cells treated with various concentrations of glucose, DHK-medicated serum, or the two in combination, was measured using a colorimetric MTT assay $(7,11)$. Briefly, the cells $(3,000$ cells/well) were seeded into 96-well plates and cultured in complete DMEM. The cells were treated with glucose at concentrations of 5, 25, 40 and $60 \mathrm{mM}$, isotonic mannitol at concentrations of 35 and $55 \mathrm{mM}$, DHK-medicated serum (1, 2, 5, 10 and $20 \%$ ) alone, and DHK-medicated serum (1, 5 and 10\%) combined with $40 \mathrm{mM}$ glucose for 48,72 and $96 \mathrm{~h}$ at $37^{\circ} \mathrm{C}$ in an atmosphere containing $5 \% \mathrm{CO}_{2}$ and $95 \%$ air. MTT solution $(5 \mathrm{mg} / \mathrm{ml} ; 10 \mu \mathrm{l})$ was added into each well containing the cells, and was incubated at $37^{\circ} \mathrm{C}$ for $4 \mathrm{~h}$ in a humidified atmosphere containing $5 \% \mathrm{CO}_{2}$ and $95 \%$ air. Following removal of the medium, formazan crystals were solubilized by adding $100 \mu 1$ of dimethylsulfoxide and oscillating for $10 \mathrm{~min}$. The absorbance at $490 \mathrm{~nm}$ was measured using a microplate reader (Multiskan GO; Thermo Fisher Scientific. Inc.).

Cell apoptosis analysis. The cells were divided into five experimental groups: Normal group (5 $\mathrm{mM}$ glucose), model group (40 mM glucose), and 1,5 or $10 \%$ medicated serum $+40 \mathrm{mM}$ glucose groups. Apoptosis was evaluated with an Annexin V/fluorescein isothiocyanate apoptosis detection kit using flow cytometry (25). The cells were detached and stained according to the manufacturer's protocol and then measured using a flow cytometer FACSCanto $^{\mathrm{TM}}$ II; BD Biosciences, Franklin Lakes, NJ, USA).

Lipid peroxidation assay. Lipid peroxidation was assayed using a TBARS method $(7,18)$. The samples collected from the culture medium were used to measure the malondialdehyde (MDA) formed in a peroxidizing lipid system. The quantities of TBARS were calculated according to a standard curve of 1,1,3, 3-tetramethoxypropane. 
Measurement of the activities of GPX and SOD. The activities of GPx and SOD in the culture medium were measured using a spectrophotometric method according to the manufacturer's protocol.

Measurement of intracellular ROS. Intracellular ROS levels were measured using the oxidation-sensitive fluorescent probe dye $\mathrm{H}_{2}$ DCFDA $(\mathrm{Ex} / \mathrm{Em}=488 \mathrm{~nm} / 525 \mathrm{~nm})$. The cell suspension was inoculated into a 96 -well plate at a density of $1 \times 10^{4}$ cells/well. The cells were rinsed with PBS and then incubated with $10 \mu \mathrm{M} \mathrm{H}_{2} \mathrm{DCFDA}$ at $37^{\circ} \mathrm{C}$ for $30 \mathrm{~min}$ according to the manufacturer's protocol. The fluorescence intensities were detected using a multiscan spectrum (2300-001M; PerkinElmer, Inc., Waltham, MA, USA) and images were captured under an inverted light microscope (BDS 300; Optec Instrument, Co., Ltd., Chongqing, China).

Western blot analysis. Western blot analysis was performed as previously described $(7,18,19,25)$. Cells grown on 6 -well plates were harvested using $200 \mu \mathrm{l}$ ice-cold Pierce Radioimmunoprecipitation Assay Buffer (Thermo Fisher Scientific, Inc.) supplemented with $10 \mu \mathrm{l} / \mathrm{ml}$ protease inhibitor cocktail (Sigma-Aldrich, Merck KGaA). Following centrifugation at $12,000 \times \mathrm{g}$ for $30 \mathrm{~min}$ at $4^{\circ} \mathrm{C}$, the supernatants were collected and the total protein content was quantified using a Bradford protein assay. A total of $50 \mu \mathrm{g}$ total protein extract was separated by SDS-PAGE on a $10 \%$ gel and transferred onto a PVDF membrane using Hoefer miniVE transfer system (170-4467; Bio-Rad Laboratories, Inc., Hercules, CA, USA). The membranes were blocked with $5 \%$ non-fat milk for $1 \mathrm{~h}$ at room temperature. The membrane was incubated with ICAM-1 antibody $(1: 1,000), \mathrm{NF}-\kappa \mathrm{B}$ p65 antibody $(1: 1,000)$, VEGF antibody $(1: 1,000)$, HIF-1 $\alpha$ antibody $(1: 1,000)$ or GAPDH $(1: 1,000)$ antibody overnight at $4^{\circ}$ following blocking. The membrane was then incubated with secondary antibodies conjugated to horseradish peroxidase at room temperature for $1 \mathrm{~h}$. The bound antibodies were detected using ECL reagent. The quantity of immunoreactive protein was assessed using scanning densitometry (1658001; Bio-Rad Laboratories, Inc). All blots were normalized with an antibody against GAPDH and average band intensities relative to total proteins were determined using Image $\mathbf{J}$ software (version 1.43; National Institutes of Health, Bethesda, MD, USA).

Statistical analysis. Each experiment was repeated at least three times. All data are expressed as the mean \pm standard error of the mean and were analyzed using the Statistical Package for the Social Sciences version 20.0 (IBM SPSS, Armonk, NY, USA). One-way analysis of variance was performed and an LSD post hoc test was used for multiple comparisons. $\mathrm{P}<0.05$ was considered to indicate a statistically significant difference.

\section{Results}

Effect of DHK-medicated serum on the viability of $H G$-treated EA. hy926 cells. Compared with the normal cells, the inhibitory rates of cell viability were 17.1, 24.9 and $37.7 \%$ when the cells were incubated with $40 \mathrm{mM}$ glucose for 48 ,

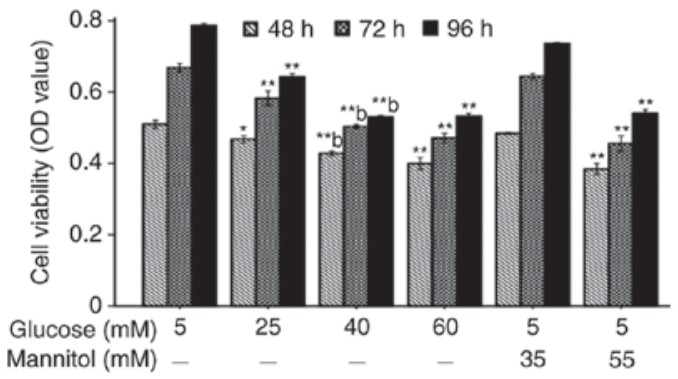

Figure 1. Viability of EA. hy926 cells treated with various concentrations of glucose and mannitol. Data are expressed as the mean \pm standard error of the mean $(\mathrm{n}=6) .{ }^{*} \mathrm{P}<0.05$ and ${ }^{* *} \mathrm{P}<0.01$, vs. $5 \mathrm{mM}$ glucose group; ${ }^{\text {b }} \mathrm{P}<0.01$, vs. corresponding isotonic group. $\mathrm{OD}$, optical density.

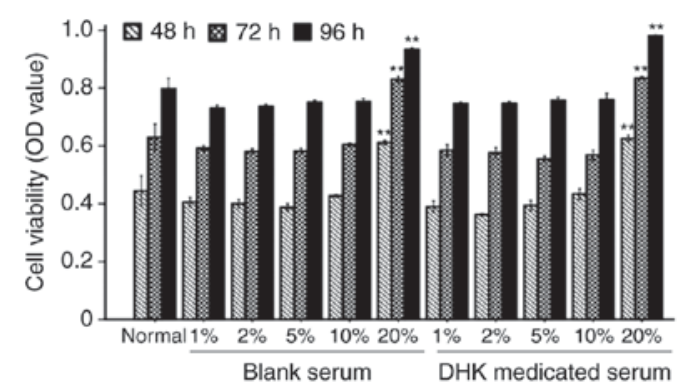

Figure 2. Effect of DHK-medicated serum on the viability of normal EA. hy926 cells. Data are expressed as the mean \pm standard error of the mean $(\mathrm{n}=6) .{ }^{* *} \mathrm{P}<0.01$, vs. normal group. DHK, Danhong Huayu Koufuye; OD, optical density.

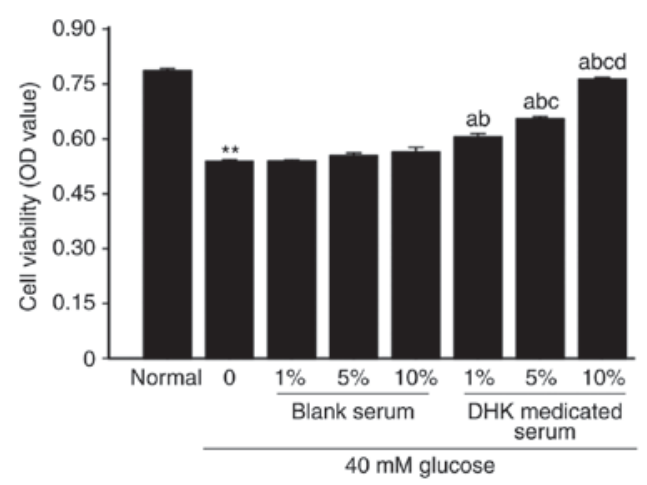

Figure 3. Effect of DHK-medicated serum on the viability of high glucose-treated EA. hy926 cells. Data are expressed as the mean \pm standard error of the mean $(n=6) .{ }^{* *} \mathrm{P}<0.01$, vs. normal group; ${ }^{a} \mathrm{P}<0.01$, vs. model group. ${ }^{b} \mathrm{P}<0.01$, vs. corresponding volume blank serum group; ${ }^{\mathrm{c}} \mathrm{P}<0.01$, vs. $1 \%$ DHK-medicated serum group; ${ }^{\mathrm{d}} \mathrm{P}<0.01$, vs. $5 \%$ DHK-medicated serum group. DHK, Danhong Huayu Koufuye; OD, optical density.

72 and 96 h, respectively (Fig. 1). Compared with the corresponding isotonic group, cell viability in the $40 \mathrm{mM}$ glucose group was significantly decreased $(\mathrm{P}<0.01)$. Therefore, the EA. hy926 cells were cultured with $40 \mathrm{mM}$ glucose for $96 \mathrm{~h}$ in the following experiments.

The viability of the normal cells was not altered by DHK-medicated serum at concentrations of $1-10 \%$ for 48, 72 and $96 \mathrm{~h}$ (Fig. 2). However, the viability of cells incubated with $40 \mathrm{mM}$ glucose for $96 \mathrm{~h}$ was increased by DHK-medicated serum in a concentration-dependent manner $(\mathrm{P}<0.01$, vs. model group; Fig. 3). 

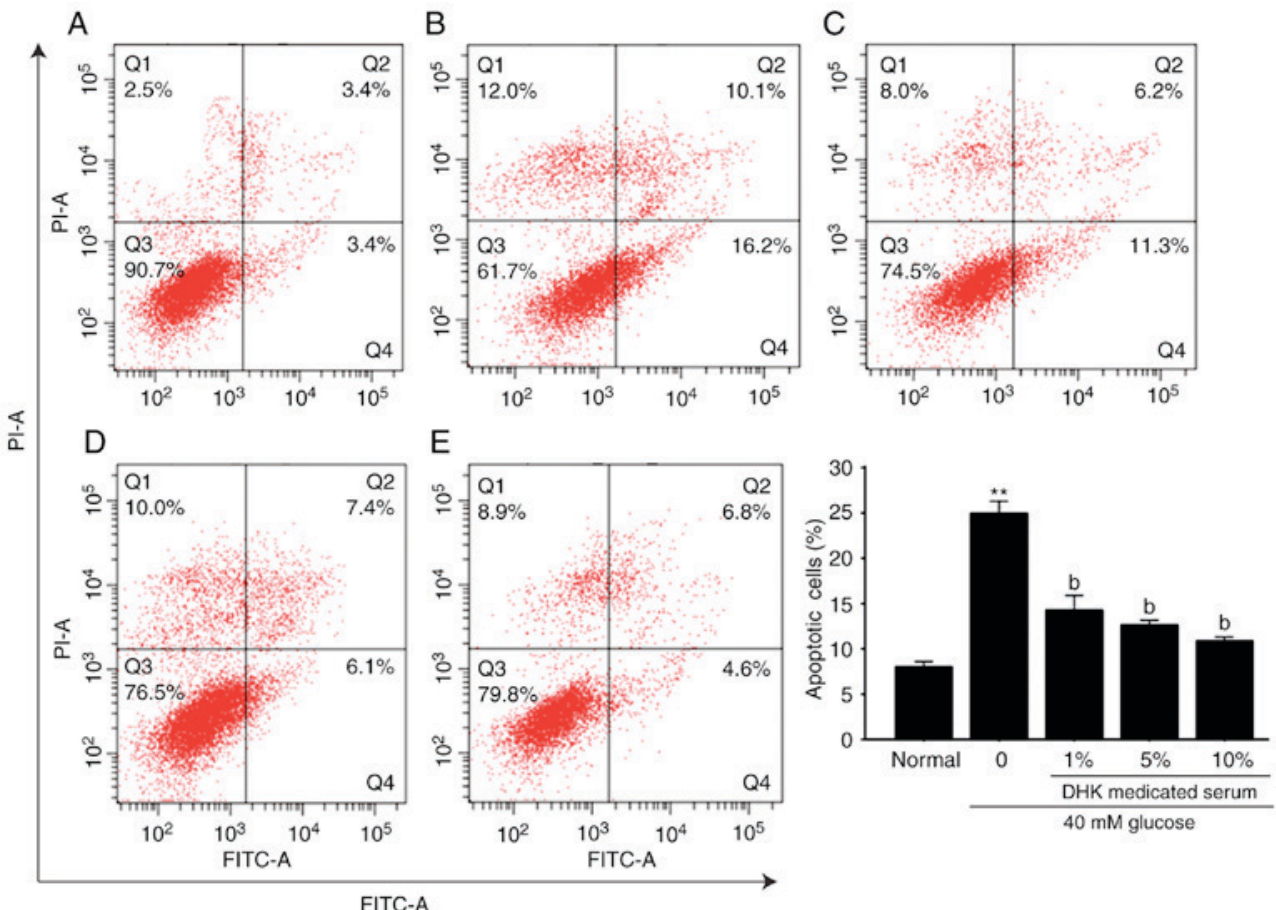

Figure 4. Effect of DHK-medicated serum on the high glucose-induced apoptosis of EA. hy926 cells. Q1, necrotic and dead cells; Q2, late apoptotic cells; Q3, living cells; Q4, early apoptotic cells. (A) normal group; (B) model group; (C) 1\% DHK-medicated serum group; (D) 5\% DHK-medicated serum group; (E) $10 \%$ DHK-medicated serum group. Data are expressed as the mean \pm standard error of the mean $(\mathrm{n}=6) .{ }^{* *} \mathrm{P}<0.01$, vs. normal group; ${ }^{\text {b }} \mathrm{P}<0.01$, vs. model group DHK, Danhong Huayu Koufuye; PI, propidium iodide; FITC, fluorescein isothiocyanate; Q, quadrant.

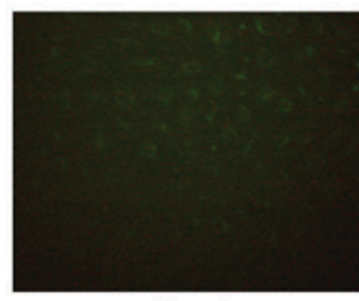

Normal

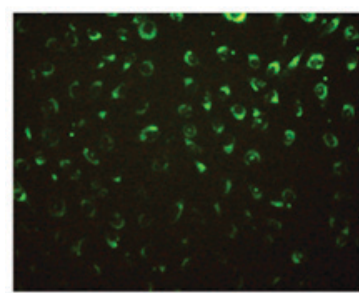

$5 \%$ DHK medicated serum

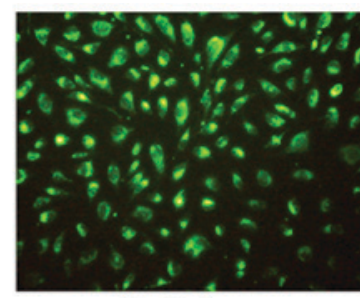

$40 \mathrm{mM}$ glucose

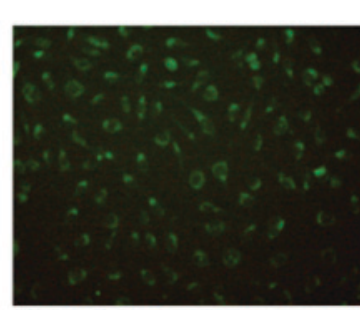

$10 \%$ DHK medicated serum

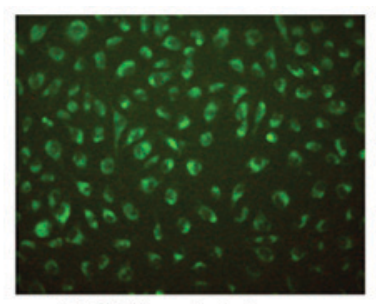

$1 \%$ DHK medicated serum

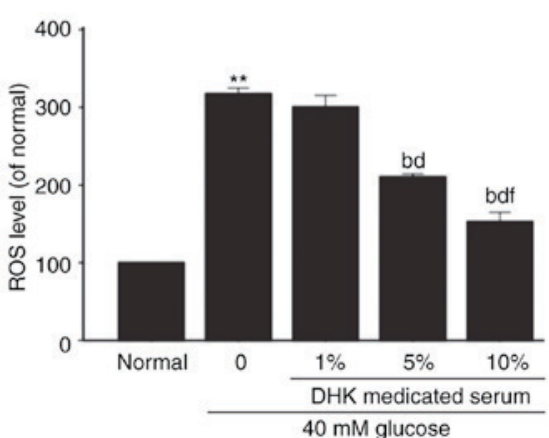

Figure 5. Effect of DHK-medicated serum on high glucose-induced ROS levels in EA. hy926 cells. Data are expressed as the mean \pm standard error of the mean $(\mathrm{n}=6)$. Magnification, $\mathrm{x} 200$. ${ }^{* *} \mathrm{P}<0.01$, vs. normal group; ${ }^{\mathrm{b}} \mathrm{P}<0.01$, vs. model group; ${ }^{\mathrm{d}} \mathrm{P}<0.01$, vs. $1 \% \mathrm{DHK}-\mathrm{medicated}$ serum group; ${ }^{\mathrm{f}} \mathrm{P}<0.01$, vs. $5 \%$ DHK-medicated serum group. DHK, Danhong Huayu Koufuye; ROS, reactive oxygen species.

Effect of DHK-medicated serum on HG-induced apoptosis of EA. hy926 cells. The incubation of EA. hy926 cells with $40 \mathrm{mM}$ glucose for $96 \mathrm{~h}$ significantly increased apoptosis $(\mathrm{P}<0.01)$, compared with that in the normal group, whereas DHK-medicated serum significantly decreased the apoptotic rate in a concentration-dependent manner. A $1 \%$ concentration of DHK-medicated serum reduced the apoptotic rate by $42.8 \%$ (Fig. 4A-E).
Effects of DHK-medicated serum on levels of ROS and MDA in HG-treated EA. hy926 cells. The intracellular ROS level in the HG-treated cells was significantly elevated by $\sim 3$-fold $(\mathrm{P}<0.01)$, compared with that in the normal group. DHK-medicated serum concentration-dependently reduced the ROS levels. DHK-medicated serum at concentrations of 5 and $10 \%$ decreased the ROS levels by 33.7 and $51.9 \%$, respectively $(\mathrm{P}<0.01$, vs. model group; Fig. 5). 


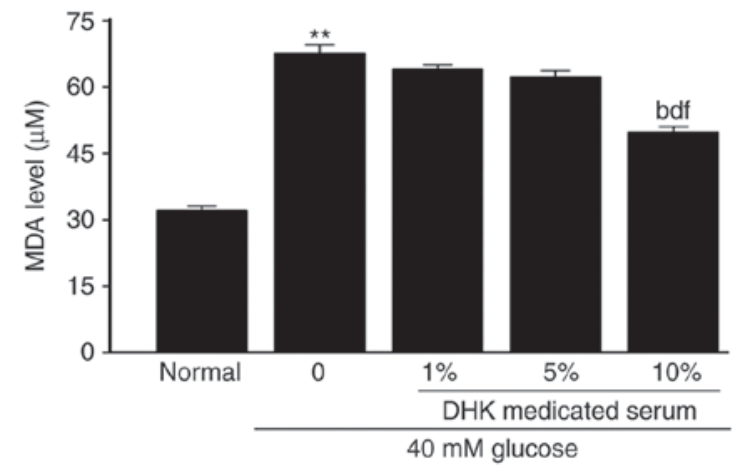

Figure 6. Effect of DHK-medicated serum on the high glucose-induced MDA level in EA. hy926 cells. Data are expressed as the mean \pm standard error of the mean $(\mathrm{n}=6) .{ }^{* *} \mathrm{P}<0.01$, vs. normal group; ${ }^{\mathrm{b}} \mathrm{P}<0.01$, vs. model group; ${ }^{\mathrm{d}} \mathrm{P}<0.01$, vs. $1 \%$ DHK-medicated serum group; ${ }^{\mathrm{f}} \mathrm{P}<0.01$, vs. $5 \%$ DHK-medicated serum group. DHK, Danhong Huayu Koufuye; MDA, malondialdehyde.
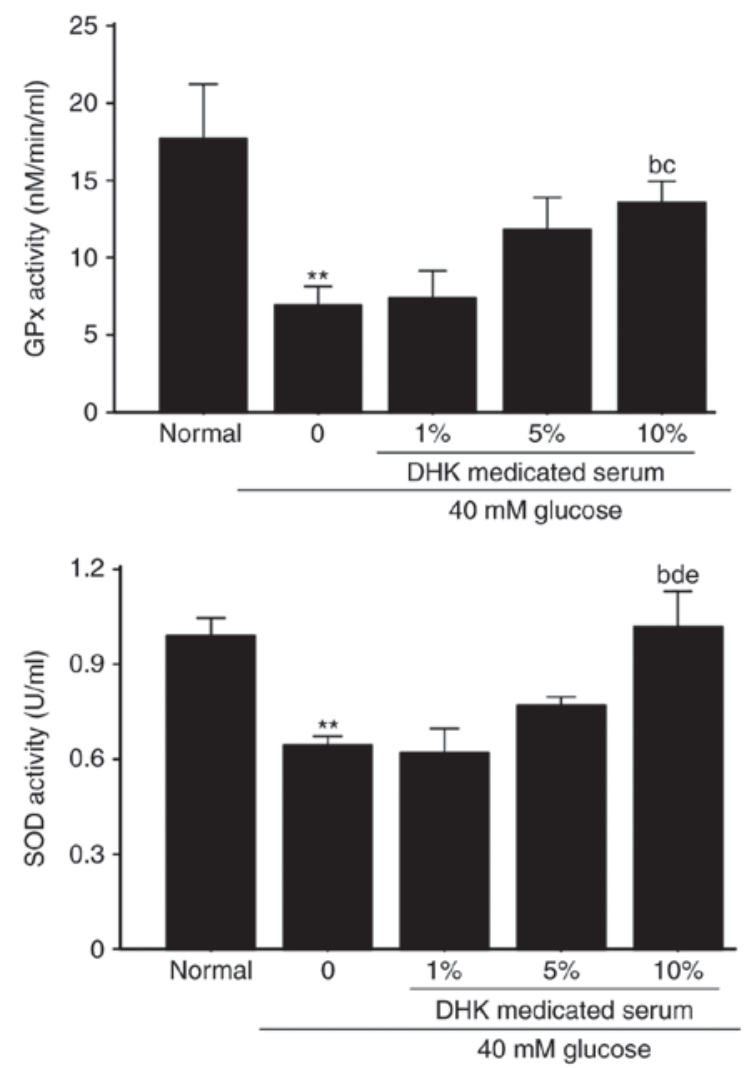

Figure 7. Effects of DHK-medicated serum on the activities of GPx and SOD in high glucose-treated EA. hy926 cells. Data are expressed as the mean \pm standard error of the mean $(\mathrm{n}=6){ }^{* * *} \mathrm{P}<0.01$, vs. normal group; ${ }^{\mathrm{b}} \mathrm{P}<0.01$ vs. model group; ${ }^{c} \mathrm{P}<0.05$ and ${ }^{\mathrm{d}} \mathrm{P}<0.01$, vs. $1 \%$ DHK-medicated serum group; ${ }^{\mathrm{e}} \mathrm{P}<0.05$, vs. 5\% DHK-medicated serum group. DHK-medicated serum group. DHK, Danhong Huayu Koufuye; GPx, glutathione peroxidase; SOD, superoxide dismutase.

Compared with the normal cells, the MDA level in the model group was significantly increased by $\sim 2$-fold $(\mathrm{P}<0.01)$. DHK-medicated serum significantly decreased the level of MDA ( $\mathrm{P}<0.01$, vs. model group; Fig. 6).

Effects of DHK-medicated serum on the activities of GPX and SOD in HG-treated cells. As shown in Fig. 7, the activities of GPx and SOD in the HG-treated EA. hy926 cells were significantly reduced by 60.8 and $35.4 \%$, respectively $(\mathrm{P}<0.01$, vs. normal group). A $10 \%$ concentration of DHK-medicated serum significantly increased the activities of GPx and SOD by 95.5 and $59.4 \%$, respectively ( $\mathrm{P}<0.01$, vs. model group).

Effects of DHK-medicated serum on protein expression levels of ICAM-1, NF- KB, HIF-1 $\alpha$ and VEGF in HG-treated EA. hy926 cells. Compared with normal cells, the protein expression levels of ICAM-1, NF- $\kappa$ B, HIF- $1 \alpha$ and VEGF in the model group were significantly increased by $\sim 3-, 1.5$-, 2.2- and 1.5-fold, respectively $(\mathrm{P}<0.01)$. DHK-medicated serum concentration-dependently decreased the protein expression levels of ICAM-1, NF- $\kappa \mathrm{B}$, HIF- $1 \alpha$ and VEGF ( $\mathrm{P}<0.05$ or $\mathrm{P}<0.01$, vs. model group; Fig. 8).

\section{Discussion}

Endothelial cell proliferation is inhibited and apoptosis is induced when the cells are exposed to a HG environment $(7,18,26)$. The results of the present study showed that cell viability was significantly decreased (Fig. 3) and apoptosis was increased (Fig. 4) when EA. hy926 cells were incubated with $40 \mathrm{mM}$ glucose for $96 \mathrm{~h}$, which suggested that the hyperglycemic cell model had been successfully established.

Elevated oxidative stress can cause injury to vascular endothelial cells during the process of diabetic vascular complications (11-13). The imbalance between the increased production of oxidants and decreased activity of antioxidants has been a focus of attention in understanding the pathological mechanisms of diabetic vascular complications $(7,10,18,27)$.

The excessive production of ROS is one of the most common contributors to endothelial damage. The hyperglycemia-induced generation of ROS is considered to be causal link between elevated glucose and the pathways of development of diabetic vascular complications (27-30). In the present study, DHK-medicated serum significantly decreased the HG-induced generation of ROS (Fig. 5). This result suggested that DHK-medicated serum reduced cell oxidative stress via inhibiting the generation of ROS and then facilitating the inhibition of endothelial cell apoptosis.

Cellular lipid peroxidation, an activity induced by oxidative stress, is known to be important in the complications of DM. Lipid peroxidation is initiated when free radicals attack membrane lipids. This attack generates increased quantities of reactive products, which have been implicated in endotheliocyte damage of tissues, including the heart, kidney and eye. MDA, a secondary product of lipid peroxidation, is a common index used to evaluate excess oxidative stress $(7,8,25)$. Excessive quantities of MDA in serum and tissues lead to the development of diabetic vascular complications $(14,15,31)$. In the present study, DHK-medicated serum led to a reduction in the level of MDA (Fig. 6), which suggested that certain antioxidant components in DHK-medicated serum contribute to the inhibition of lipid peroxide production.

The free radicals created from the metabolic system cause injury to cell membranes and ageing of the body, and induce vascular diseases. The antioxidant status in diabetic patients is crucial in preventing oxidative stress and vascular complications. Antioxidative enzymes, including SOD, GPx and CAT, inhibit ROS generation. SOD is a major antioxidant enzyme, which protects endothelial cells from damage (32-35). GPx reduces 

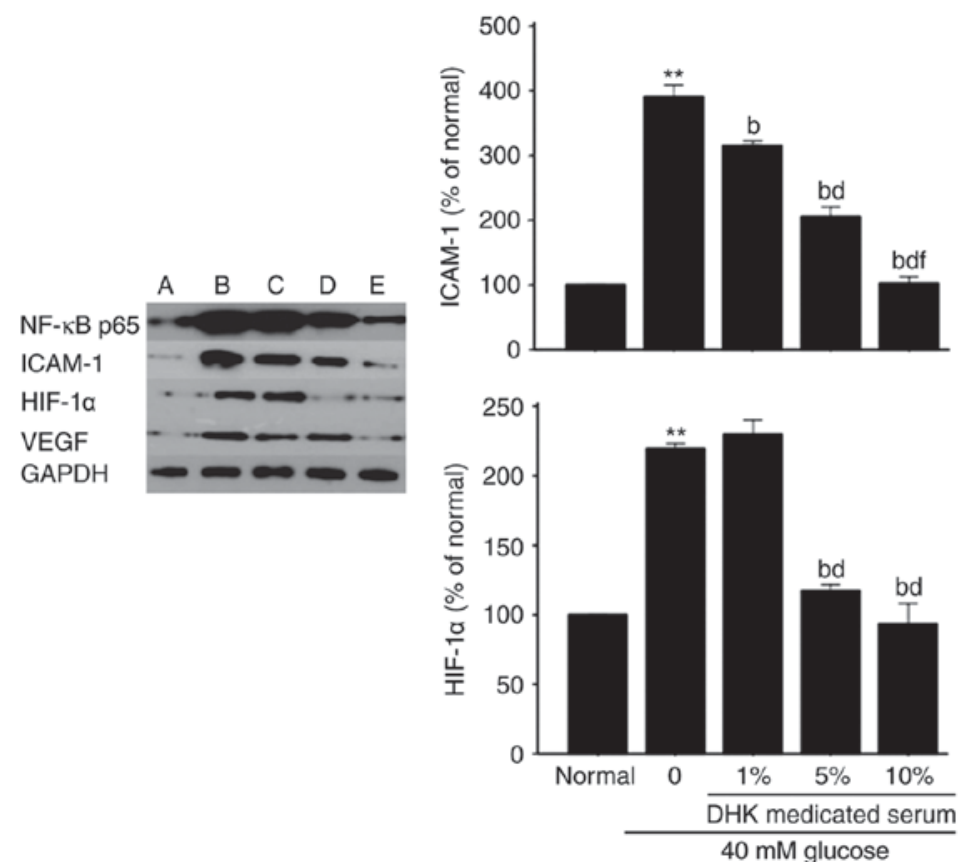
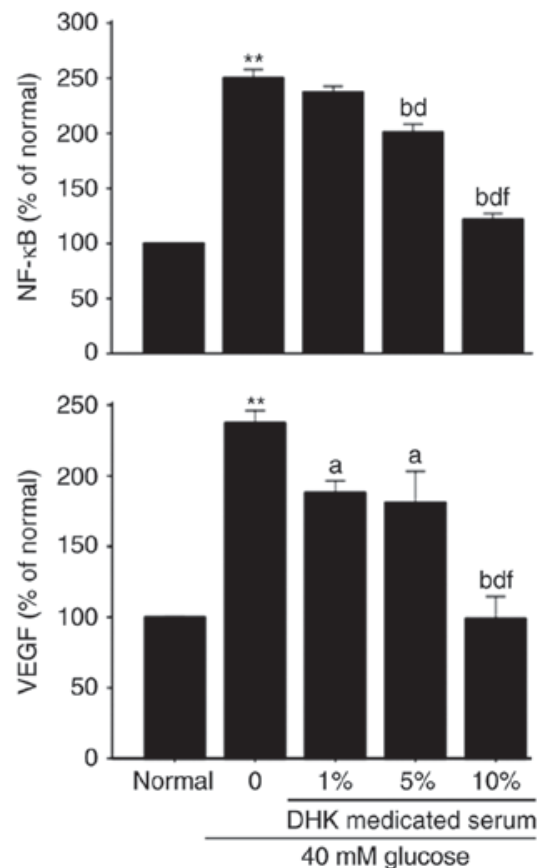

Figure 8. Effects of DHK-medicated serum on protein expression levels of ICAM-1, NF-кB, HIF-1 $\alpha$ and VEGF in high glucose-treated EA. hy926 cells. Data are expressed as the mean \pm standard error of the mean $(n=6)$. (A) Normal group; (B) model group; (C) 1\% DHK-medicated serum group; (D) 5\% DHK-medicated serum group; (E) $10 \%$ DHK-medicated serum group. ${ }^{* *} \mathrm{P}<0.01$, vs. normal group; ${ }^{\mathrm{a}} \mathrm{P}<0.05$, vs. model group; ${ }^{\text {b }} \mathrm{P}<0.01$, vs. model group; ${ }^{\mathrm{d}} \mathrm{P}<0.01$,

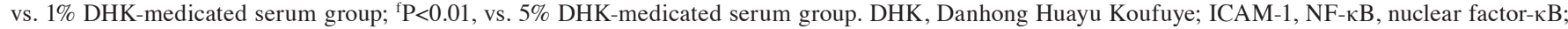
HIF-1 $\alpha$, hypoxia-inducible factor-1 $\alpha$; VEGF, vascular endothelial growth factor; GAPDH, glyceraldehyde-3-phosphate dehydrogenase.

the numbers of free radicals, and SOD works in conjunction with CAT and GPx to reduce ROS levels. The results of the present study revealed that the activities of SOD and GPX were significantly decreased in the HG-treated EA. hy926 cells, which was consistent with previous reports $(7,32)$. The DHK-medicated serum increased the activities of these enzymes (Fig. 7), which indicated that DHK-medicated serum attenuated $\mathrm{HG}$-induced oxidative stress to maintain the stability of vascular endotheliocytes.

Endothelial function can be impaired by ROS via numerous mechanisms, including lipid peroxidation, activation of $\mathrm{NF}-\kappa \mathrm{B}$, and inactivation of $\mathrm{NO}(7,8)$. In addition to biomarkers of oxidative stress, inflammatory substances are responsible for the development of vascular complications in diabetic patients $(10,18,20)$. The $N F-\kappa B$ transcription factor has been recognized as an important controller of the inflammatory process (33-36). In the present study, the protein expression of $\mathrm{NF}-\kappa \mathrm{B}$ was high in HG-treated cells and was inhibited by treatment with DHK-medicated serum (Fig. 8). This indicated that DHK suppressed the expression of $\mathrm{NF}-\kappa \mathrm{B}$ p65 in the diabetic endothelial inflammation process.

The levels of ICAM-1 are increased through the activation of $N F-\kappa B$, which is a crucial mechanism of cell injury when exposed to a HG environment, and an important event during the inflammatory process of diabetic vascular complications $(34,35,37)$. In line with previous reports $(35,37)$, the present study found that the protein expression of ICAM-1 was high in the HG-treated cells. DHK-medicated serum notably downregulated the protein expression of ICAM-1 (Fig. 8), which suggested that DHK-medicated serum protected vascular endothelial cells from injury via its anti-inflammatory effects.
Diabetic factors result in the production of HIF-1 $\alpha$ and angiogenesis (38). The high expression of VEGF, induced by hyperglycemia, is one of the most important pathophysiological stimuli in diabetic vascular complications $(39,40)$. The expression of VEGF appears to be regulated through two interdependent pathways: Directly via HIF-1 $\alpha$ and indirectly via the activation of NF- $\mathrm{KB}$. In the present study, the protein expression levels of VEGF and HIF-1 $\alpha$ were upregulated by HG in the cells, and this was reversed by DHK-medicated serum (Fig. 8). These results suggested that DHK protected the endothelial cells from damage via inhibiting the activation of HIF-1 $\alpha$ and VEGF.

In conclusion, the present study showed that DHK-medicated serum had a marked effect on inhibiting HG-induced oxidative stress and inflammation in EA. hy926 cells, which may be important mechanisms underlying the effect of DHK in preventing diabetic vascular complications in STZ-induced diabetic rats and ZDF rats.

\section{Acknowledgements}

This study was financially supported by the National Natural Science Foundation of China (grant no. 81303282) and the Department of Education of Guangdong Province (grant no. Yq2013044).

\section{References}

1. Ziberna L, Martelanc M, Franko M and Passamonti S: Bilirubin is an endogenous antioxidant in human vascular endothelial cells. Sci Rep 6: 29240, 2016.

2. Choi ES, Lee YJ, Seo CS, Yoon JJ, Han BH, Park MC, Kang DG and Lee HS: Vascular protective role of Samul-Tang in HUVECs: Involvement of Nrf2/HO-1 and NO. Evid Based Complement Alternat Med 2016: 9580234, 2016. 
3. Daiber A, Steven S, Weber A, Shuvaev VV, Muzykantov VR, Laher I, Li H, Lamas S and Münzel T: Targeting vascular (endothelial) dysfunction. Br J Pharmacol 174: 1591-1619, 2017.

4. Rask-Madsen C and King GL: Vascular complications of diabetes: Mechanisms of injury and protective factors. Cell Metab 17: 20-33, 2013.

5. Sotníková R, Nedelčevová J, Navarová J, Nosálová V, Drábiková K, Szöcs K, Křenek P, Kyseĺlová Z, Bezek S, Knezl V, et al: Protection of the vascular endothelium in experimental situations. Interdiscip Toxicol 4: 20-26, 2011

6. Auger C, Said A, Nguyen PN, Chabert P, Idris-Khodja N and Schini-Kerth VB: Potential of food and natural products to promote endothelial and vascular health. J Cardiovasc Pharmacol 68: 11-18, 2016.

7. Jayakumar T, Chang CC, Lin SL, Huang YK, Hu CM, Elizebeth AR, Lin SC and Choy CS: Brazilin ameliorates high glucose-induced vascular inflammation via inhibiting ROS and CAMs production in human umbilical vein endothelial cells Biomed Res Int 2014: 403703, 2014.

8. Jain SK: Superoxide dismutase overexpression and cellular oxidative damage in diabetes. A commentary on 'Overexpression of mitochondrial superoxide dismutase in mice protects the retina from diabetes-induced oxidative stress'. Free Radic Biol Med 41: 1187-1190, 2006

9. Muscoli C, Mollace V, Wheatley J, Masini E, Ndengele M Wang ZQ and Salvemini D: Superoxide-mediated nitration of spinal manganese superoxide dismutase: A novel pathway in N-methylDaspartate-mediated hyperalgesia. Pain 111: 96-103, 2004

10. Pitocco D, Tesauro M, Alessandro R, Ghirlanda G and Cardillo C: Oxidative stress in diabetes: Implications for vascular and other complications. Int J Mol Sci 14: 21525-21550, 2013.

11. Kanikarla-Marie P and Jain SK: Hyperketonemia (acetoacetate) upregulates NADPH oxidase 4 and elevates oxidative stress, ICAM-1, and monocyte adhesivity in endothelial cells. Cell Physiol Biochem 35: 364-373, 2015.

12. Sheu ML, Ho FM, Yang RS, Chao KF, Lin WW, Lin-Shiau SY and Liu SH: High glucose induces human endothelial cell apoptosis through a phosphoinositide 3-kinase-regulated cyclooxygenase-2 pathway. Arterioscler Thromb Vasc Biol 25: 539-545, 2005.

13. Ihnat MA, Thorpe JE, Kamat CD, Szabó C, Green DE, Warnke LA, Lacza Z, Cselenyák A, Ross K, Shakir S, et al: Reactive oxygen species mediate a cellular 'memory' of high glucose stress signalling. Diabetologia 50: 1523-1531, 2007.

14. Palem SP and Abraham P: A Study on the level of oxidative stress and inflammatory markers in type 2 diabetes mellitus patients with different treatment modalities. J Clin Diagn Res 9: BC04-BC07, 2015.

15. Pereira EC, Ferderbar S, Bertolami MC, Faludi AA, Monte O, Xavier HT, Pereira TV and Abdalla DS: Biomarkers of oxidative stress and endothelial dysfunction in glucose intolerance and diabetes mellitus. Clin Biochem 41: 1454-1460, 2008.

16. Fratantonio D, Speciale A, Canali R, Natarelli L, Ferrari D, Saija A, Virgili $F$ and Cimino F: Low nanomolar caffeic acid attenuates high glucose-induced endothelial dysfunction in primary human umbilical-vein endothelial cells by affecting NF- $\kappa \mathrm{B}$ and $\mathrm{Nrf} 2$ pathways. Biofactors 43: 54-62, 2017.

17. Min SW and Han JS: Effect of Polyopes lancifolia extract on oxidative stress in human umbilical vein endothelial cells induced by high glucose. Prev Nutr Food Sci 18: 38-44, 2013.

18. Jiang Y,Li Y,Ding Y, Dai X, Ma X, Bao L,Zhang Z and Li Y: Grape seed proanthocyanidin extracts prevent high glucose-induced endothelia dysfunction via PKC and $\mathrm{NF}-\kappa \mathrm{B}$ inhibition. Biosci Biotechnol Biochem 79: 1493-1503, 2015.

19. Mudaliar H, Pollock C, Ma J, Wu H, Chadban S and Panchapakesan U: The role of TLR2 and 4-mediated inflammatory pathways in endothelial cells exposed to high glucose. PLoS One 9: e108844, 2014.

20. Zheng X, Zhu S, Chang S, Cao Y, Dong J, Li J, Long R and Zhou Y: Protective effects of chronic resveratrol treatment on vascular inflammatory injury in streptozotocin-induced type 2 diabetic rats: Role of NF-kappa B signaling. Eur J Pharmacol 720: 147-157, 2013.

21. Lin BQ, Zhou JY, Ma Y, Deng YJ,Zheng CJ and Lin JL: Preventive effect of danhong huayu koufuye on diabetic retinopathy in rats. Int J Ophthalmol 4: 599-604, 2011.
22. Lin BQ, Zhong CM, Lin JL, Hu LY, Chen WP and Zhang ZY: Effect of danhong huayu oral liquid combined with insulin on prevention and progression of early diabetic cardiomyopathy in rats. Zhong Yao Cai 37: 1218-1221, 2014 (In Chinese).

23. Chen WP, Wang YD, Ma Y, Zhang ZY, Hu LY, Lin JL and Lin BQ: Danhong Huayu Koufuye combined with metformin attenuated diabetic retinopathy in Zucker diabetic fatty rats. Int J Ophthalmol 8: 1094-1100, 2015.

24. Zhang Z, Hu L, Chen W, Zhou C, Gui G and Lin B: Danhong huayu koufuye prevents deep vein thrombosis through anti-inflammation in rats. J Surg Res 201: 340-347, 2016.

25. Hao XL, Kang Y, Li JK, Li QS, Liu EL and Liu XX: Protective effects of hyperoside against $\mathrm{H} 2 \mathrm{O} 2$-induced apoptosis in human umbilical vein endothelial cells. Mol Med Rep 14: 399-405, 2016.

26. Lee YJ, Kang DG, Kim JS and Lee HS: Buddleja officinalis inhibits high glucose induced matrix metalloproteinase activity in human umbilical vein endothelial cells. Phytother Res 22: $1655-1659,2008$

27. Thomas SR, Witting PK and Drummond GR: Redox control of endothelial function and dysfunction: Molecular mechanisms and therapeutic opportunities. Antioxid Redox Signal 10: 1713-1765, 2008.

28. Xu Q, Zhang B, Li XM and Gao X: Traditional Chinese medicine formula Qing Huo Yi Hao as superoxide anion scavenger in high glucose-treated endothelial cells. Acta Pharmacol Sin 33: 496-502, 2012.

29. Peng XL, Qu W, Wang LZ, Huang BQ, Ying CJ, Sun XF and Hao LP: Resveratrol ameliorates high glucose and high-fat/sucrose diet-induced vascular hyperpermeability involving Cav-1/eNOS regulation. PLoS One 9: e113716, 2014.

30. Xu Q, Xia P, Li X, Wang W, Liu Z and Gao X: Tetramethylpyrazine ameliorates high glucose-Induced endothelial dysfunction by increasing mitochondrial biogenesis. PLoS One 9: e88243, 2014.

31. Maithili Karpaga Selvi N, Sridhar MG, Swaminathan RP and Sripradha R: Curcumin attenuates oxidative stress and activation of redox-sensitive kinases in high fructose- and high-fat-fed male Wistar rats. Sci Pharm 83: 159-175, 2014.

32. Dogan A, Celik I and Kaya MS: Antidiabetic properties of lyophilized extract of acorn (Quercus brantii Lindl.) on experimentally STZ-induced diabetic rats. J Ethnopharmacol 176: 243-251, 2015.

33. Koziel A, Sobieraj I and Jarmuszkiewicz W: Increased activity of mitochondrial uncoupling protein 2 improves stress resistance in cultured endothelial cells exposed in vitro to high glucose levels. Am J Physiol Heart Circ Physiol 309: H147-H156, 2015

34. Li J, Chen S, Cai X, Wang H, Wang X and Wang W: TLR2 expression doesn't change in ox-LDL mediated inflammation in Human umbilical vein endothelial cells under high glucose culture. Int J Clin Exp Med 8: 22004-22010, 2015.

35. Kim MH, Kang HM, Kim CE, Han S and Kim SW: Ramipril inhibits high glucose stimulated up-regulation of adhesion molecules via the ERK1/2 MAPK signaling pathway in human umbilical vein endothelial cells. Cell Mol Biol Lett 20: 937-947, 2015.

36. Liu YS, Xu DL, Huang ZW, Hao L, Wang X and Lu QH: Atorvastatin counteracts high glucose-induced Krüppel-like factor 2 suppression in human umbilical vein endothelial cells. Postgrad Med 127: 446-454, 2015.

37. Haubner F, Lehle K, Münzel D, Schmid C, Birnbaum DE and Preuner JG: Hyperglycemia increases the levels of vascular cellular adhesion molecule-1 and monocyte-chemoattractant-protein-1 in the diabetic endothelial cell. Biochem Biophys Res Commun 360: 560-565, 2007.

38. Xu X, Chen P, Zheng Q, Wang Y and Chen W: Effect of pioglitazone on diabetic nephropathy and expression of HIF-1 $\alpha$ and VEGF in the renal tissues of type 2 diabetic rats. Diabetes Res Clin Pract 93: 63-69, 2011.

39. Li J, Zhao SZ, Wang PP, Yu SP, Zheng Z and Xu X: Calcium mediates high glucose-induced HIF-1 $\alpha$ and VEGF expression in cultured rat retinal Müller cells through CaMKII-CREB pathway. Acta Pharmacol Sin 33: 1030-1036, 2012.

40. Zhang L, Zhang ZK and Liang S: Epigallocatechin-3-gallate protects retinal vascular endothelial cells from high glucose stress in vitro via the MAPK/ERK-VEGF pathway. Genet Mol Res 15, 2016. 